\title{
Reining in patient and individual choice
}

Patient choice, we might think, is the popular version of the ideas of informed consent and the principle of respect for autonomy and intimately connected to the politics of liberal individualism. There are various accounts to be given for why patient choice, in all its forms, has dominated thinking in bioethics and popular culture. All of them, I suggest, will make reference to the decline of paternalism. The bad old days of 'doctor knows best' are gone and were replaced by the primacy of patient choice and informed consent.

The response to the dominance of the principle of patient choice has been slow in building but it has come in a number of ways. Two sets of papers in this issue of the Journal of Medical Ethics show just how far this response has come and the degree to which the pendulum is swinging back in the other direction. Neil Levy's Feature article, 'Forced to be free? Increasing patient autonomy by constraining it', argues that we should go to greater lengths to correct patients' mistaken decisions (see page 293, Editor's Choice). In the 'Author meets critics' section, Sarah Conly's book, Against Autonomy: Justifying Coercive Paternalism is the focus of comment (see page 349). Both authors draw on a similar range of empirical evidence to undermine the sanctity of patient and individual choice. An array of commentators draw on these target pieces to give a clear picture of the ways in which the popular view can justifiably be undermined.

Levy's paper focuses on the process of informed consent in clinical contexts. He argues that, while this process is crucially important, it systematically fails because of well-documented frailties of human reason. The evidence of these frailties comes from cognitive and social psychology, on biases and heuristics. The key question is how we handle the systematic errors that patients make in this setting. We could accept that these mistakes are a given and carry on as before. We could reject the consent process in certain cases-we realise that individuals will make these mistakes and not offer them a choice. Finally, we can try harder by countering, in various ways, the tendencies to fall victim to these traps of reasoning.

Conceding the inevitability of these mistakes is for Levy not an option but neither, really, is the possibility of disregarding the consent process. He does however think we should put substantial pressure on it and in concluding that we should try harder, he suggests a number of practical steps that might help in applying pressure to patients to adjust their view and their choices. One practical step is the introduction of trained informed consent specialists who are equipped to recognise and point out biases and confounders in patient's reasoning. Importantly part of the role of these specialists would be to challenge patients when they make poor decisions by engaging in argument and by making it clear where the deficiencies in their reasoning lies.

Art Caplan wholeheartedly agrees with Levy and thinks that there is nothing wrong with applying a bit of pressure-clinicians should be in a position to tell you "what they would do if that was their mother in that bed". He adds to the list of frailties that Levy has documented and broadens them to include more context specific failures like the therapeutic misconception (see page 301). J D Trout also agrees with Levy and makes some suggestions that extend Levy's practical applications (see page 303). Trout's proposed applications seem slightly distinct from Levy's: that we should consider making poor decision-making more difficult by prolonging it or otherwise it more effortful. On the face of it these distinctions might be a fraction coercive.

Jan Narveson is more sceptical and takes Levy to task in a number of places (see page 302). A key target is the idea that we can uncontroversially read off what counts as rational and irrational: to use Levy's example, that there is a settled limit on a rational (as opposed to an irrational) discount rate. A second concern involves reasserting the idea that the patient, not the informed consent specialist, is the final arbiter of what they value: "The individual expresses his preferences; they aren't available for examination independently of his tendencies to express them." In line with this, might we not suspect that there is some important value in wrestling with short term pleasures, fighting fear oneself both for the sake of ones longer term goals? This value lies in the value of deciding for oneself not in getting it right or wrong, even by one's own lights. Levy's response pushes back on these ideas (see page 304$)$. He is much more confident that individuals have a settled set of values that can be gleaned from their behaviour: "selves are relatively stable, and so are their values".

Conly's book goes further along this path. Indeed Against Autonomy: Justifying Coercive Paternalism grasps the nettle that Levy is not prepared to do. ${ }^{1}$ In Conly's book we are again given a corrected view of our humanity-we are not perfectly rational and our desires and values do not all line up in a neat and orderly fashion. We need help, paternalistic help, in making sure that we have the best chance to satisfy our most treasured goals.

For Conly, this help should come from the state. Because of what we know about the decisions that individuals make, governments are justified in banning cigarettes, limiting fast-food portion sizes and banning trans-fats. Importantly, these steps are not justified because they represent a clear account of the good life but are keyed to the desires of the individual: "If the means you choose are manifestly at odds with the ends you want to achieve, I have a standard by which I can criticize your choice: it simply won't get you where you want to go.” (see page 354).

Jonathan Pugh suggests that the boundary between coercive paternalism and perfectionism in not as marked as Conly suggests (see page 350). Both Pugh and Conly agree that perfectionism is clearly to be resisted and so whether Conly's view is perfectionism is disguise matters. Conly's view is that coercive paternalism is designed to promote ends that the agent already values not to impose values, calmed to be objective, on agents. Pugh asks whether there is vast difference between the imposition of an objective value and the imposition of a ranking of values. So it might be that an individual does value health but doesn't always value it above everything else. In particular, they don't always value it above the pleasures of indulging in something unhealthy.

Alan Wertheimer's commentary examines the connections between Conly's suggestions about state interventions and those in the clinical context (see page 351). In doing so we are taken directly back to the considerations raised by Levy. Wertheimer uses the example of payment of research subjects: he worries that the paternalistic motives of 
IRBs in their concern to protect subjects from errors in thinking is misplaced and denies them the benefits of participation.

Again, the question of perfectionism and its relationship to coercive paternalism is raised, but here in the form of the distinction between hard and soft paternalism. Wertheimer is worried that Conly's insistence that she is only dealing with soft paternalism means that she is much more favourably disposed to autonomy than the title of her book would imply. Indeed, it would appear that the evidence of the natural, cognitive deficiencies exhibited in our behaviour cause problems for the autonomous nature of our actions: the reason the state is justified in taking these 'protective steps' is because the individual's view of their good is compromised, rather than being mistaken.

Gerald Dworkin considers the idea that paternalistic interventions constitute an insult to the agent and in this way the agent is not treated with respect (see page 352). The issue, then, "is whether the expression by the government, addressed to a group of individuals, e.g. all motorcycle riders, is insulting and a failure to respect the members of the group." Dworkin concludes that the insult argument fails. The government is not claiming that the motorcycle riders' conception of the good is flawed but that as a group, they are systematically mistaken about the risks. For Dworkin, this does not constitute an insult.

Nir Eyal raises questions about Conly's account of what people truly want and how this fits with what will make them happy (see page 353). In a similar way to Narveson in response to Levy, he wants to make space for individuals to genuinely and deeply value things that are not good for them. For Eyal though, Conly's book forces us "to reconsider the odd primacy that we assign autonomy."

In all of this, the basic terrain is familiar: this is paternalism versus autonomy with all the attendant nuances. When should the clinician's or the government's view of the patient's good, trump the patient's view of patient's good? ${ }^{2}$ Insofar as both authors offer us versions of soft-paternalism, their answer to this question looks to be: when the patient's view of their good is compromised by cognitive bias.
The importance of these discussions in this issue is threefold. First, both Levy and Conly apply important empirical findings from cognitive and social psychology to these clinical and public health contexts in a way that reframes paternalism. Second, there is an important reflexivity in the ways in which the empirical findings play out in the Levy's clinical context and Conly public health one. Conly's paternalistic impulses look stronger than Levy's but this may well be because of the contextual differences-in her response to Wertheimer, Conly is reticent about how her arguments would work in the clinical context. Finally, these discussions provide an important touchstone for where we are on arc of the pendulum as it swings between back from the primacy of patient choice-for good or ill.

\section{REFERENCES}

1 Conly S. Against Autonomy: Justifying Coercive Paternalism. Cambridge: Cambridge University Press, 2012.

2 Sheehanr M. Deflating autonomy. In: Häyri M, Takala T, eds. Scratching the Surface of Bioethics. Amsterdam: Rodopi Publishers, 2003. 